\title{
Evaluación de Cuatro Tiempos de Cultivo sobre la Tasa de Maduración y División Posfecundación in vitro de Ovocitos de Alpaca
}

\author{
Effect of Time of Incubation on Nuclear Maturation and Cleavage Post \\ in Vitro Fertilization of Alpaca Oocytes
}

\author{
Wilfredo Huanca L. ${ }^{1,3}$, Rosario Condori P. ${ }^{1}$, María Chileno M. ${ }^{1}$, Pedro García H. ${ }^{2}$, \\ Juan Cainzo C. ${ }^{2}$, Juan J. Becerra G. ${ }^{2}$
}

\section{RESUMEN}

\begin{abstract}
Se evaluó el efecto del tiempo de cultivo sobre la tasa de maduración nuclear y tasa de división posfecundación a 72 horas de ovocitos de alpacas. Complejos CumulusOvocitos (CCOs) fueron obtenidos de ovarios procedentes de animales beneficiados en el camal y transportados a $35{ }^{\circ} \mathrm{C}$ en solución salina $0.9 \%$ suplementada con antibiótico antimicótico. Los CCOs fueron aspirados de folículos de 2 a $6 \mathrm{~mm}$. Experimento 1: 502 ovocitos fueron distribuidos en cuatro tiempos de maduración (30, 34, 38 y 42 horas) y madurados en TCM-199 suplementado con $10 \%$ suero fetal bovino (SFB), $0.5 \mu \mathrm{g} / \mathrm{mL} \mathrm{de}$ FSH, $10 \mu \mathrm{g} / \mathrm{mL}$ de hCG, $0.2 \mathrm{mM}$ de piruvato de sodio, $50 \mu \mathrm{g} / \mathrm{mL}$ de gentamicina y $1 \mu \mathrm{g} / \mathrm{mL}$ de $\mathrm{E} 2$, y cultivados a $39^{\circ} \mathrm{C}$ bajo una atmósfera de $5 \%$ de $\mathrm{CO}_{2}$ y alta humedad. Posteriormente, los ovocitos fueron removidos, lavados con PBS suplementado con $10 \%$ de SFB y $1 \mathrm{mg} / \mathrm{ml}$ de hialuronidasa y fijados en solución de etanol y ácido acético (3:1). Los ovocitos fueron colocados en portaobjetos, teñidos con $1 \%$ de orceína y examinados bajo un microscopio a 400x para determinar la maduración nuclear. Experimento 2: 533 ovocitos fueron cultivados bajo las mismas condiciones del experimento $1 \mathrm{y}$ fecundados con espermatozoides obtenidos de epidídimos. Los espermatozoides fueron centrifugados a $700 \mathrm{~g}$ en una gradiente de Percoll discontinua (22.5:45\%) por 25 minutos. El sobrenadante fue removido y el pellet (con espermatozoides viables) reconstituido con TL-Stock. Los gametos fueron co-cultivados por 18 horas a $39^{\circ} \mathrm{C}$ con $5 \%$ de $\mathrm{CO}_{2}$ en $\mathrm{KSOM}$ suplementado con $10 \%$ de SFB, $2 \mathrm{mM}$ de piruvato de sodio y $50 \mu \mathrm{g} / \mathrm{mL}$ gentamicina, y evaluados
\end{abstract}

\footnotetext{
${ }^{1}$ Laboratorio de Reproducción Animal, Facultad de Medicina Veterinaria, Universidad Nacional Mayor de San Marcos, Lima, Perú

${ }^{2}$ Departamento de Patología Animal, Unidad de Reproducción Animal, Universidad Santiago de Compostela, España

${ }^{3}$ E-mail: whuanca2002@yahoo.com
}

Recibido: 7 de noviembre de 2013

Aceptado para publicación: 28 de agosto de 2014 
a las 72 horas. En el Experimento 1 se obtuvo el $26.3 \pm 5.4,52.6 \pm 6.7,68.5 \pm 10.6$ y $75.3 \pm 11.9 \%$ de ovocitos en Metafase-II para 30, 34, 38 y $42 \mathrm{~h}$ de cultivo, respectivamente, con diferencia estadística entre 30 y $34 \mathrm{~h}$ respecto a 38 y $42 \mathrm{~h}(\mathrm{p}<0.05)$. En el Experimento 2, la tasa de división fue $9.5 \pm 4.8,8.1 \pm 5.8,15.6 \pm 9.2$ y $19.8 \pm 8.0 \%$ para $30,34,38$ y $42 \mathrm{~h}$, sin diferencia estadística entre grupos. Los resultados sugieren que los ovocitos de alpacas requieren de 38 a 42 h de maduración para obtener estadios de Metafase-II.

Palabras clave: fecundación in vitro, ovocitos, maduración, alpacas

\section{Abstract}

The study was carried out to evaluate the effect of incubation time on nuclear maturation and cleavage rate of alpaca oocytes after 72 hours post-fertilization. Cumulusoocyte complexes (CCOs) were collected from ovaries collected at slaughterhouse and transported in saline solution $0.9 \%$ with antibiotic antimycotic at $35{ }^{\circ} \mathrm{C}$. CCOs were aspirated from 2-6 mm follicles. Experiment 1: 502 oocytes were distributed in four maturation times $(30,34,38,42$ hours), matured in TCM-199 supplemented with $10 \%$ fetal calf serum (FCS) (v:v), $0.5 \mu \mathrm{g} / \mathrm{mLFSH}, 10 \mu \mathrm{g} / \mathrm{mLhCG}, 0.2 \mathrm{mM}$ sodium pyruvate, $50 \mu \mathrm{g} / \mathrm{mL}$ gentamicine and $1 \mu \mathrm{g} / \mathrm{mL}$ oestradiol, and cultivated at $39^{\circ} \mathrm{C}$ in an atmosphere of $5 \% \mathrm{CO} 2$ and high humidity. After maturation, CCOs were removed from maturation medium and washed with PBS supplemented with $10 \% \mathrm{FCS}$ and $1 \mathrm{mg} / \mathrm{ml}$ of hyaluronidase, and fixed in ethanol and acetic acid (3:1). Oocytes were placed on a glass slide, stained with $1 \%$ orcein and examined under microscope at 400x to evaluate nuclear maturation status. Experiment 2: $533 \mathrm{CCOs}$ were culture under similar maturation protocols than experiment 1 and fertilized with epididymal spermatozoa. These were obtained by centrifugation at $700 \mathrm{~g}$ on a Percoll discontinuous gradient $(22.5: 45 \%)$ for $25 \mathrm{~min}$. The supernatant was removed by aspiration and the pellet (containing viable spermatozoa) was re-suspended in TL Stock. Gameteswereco-incubated for $18 \mathrm{~h}$ at $39^{\circ} \mathrm{C}$ with $5 \% \mathrm{CO}_{2}$ and cultivated in KSOM supplemented with $10 \%$ FCS (v:v), $0.2 \mathrm{mM}$ sodium pyruvate and $50 \mu \mathrm{g} / \mathrm{ml}$ gentamicine, and evaluated in 72 hours. In experiment 1, 26.3 $\pm 5.4,52.6 \pm 6.7,68.5 \pm 10.6$ and $75.3 \pm 11.9 \%$ of oocytes were in M-II stage for the $30,34,38$, and $42 \mathrm{~h}$ of culture respectively, with significant difference between 30 and 34 with respect to 38 and $42 \mathrm{~h}$ ( $\mathrm{p}<0.05)$. In experiment 2 , the cleavage rate was $9.5 \pm 4.8,8.1 \pm 5.8,15.6 \pm 9.2$ and $19.8 \pm 8.0 \%$ for $30,34,38$, and $42 \mathrm{~h}$ after culture, and without statistical difference between groups. These results indicate that is required $38-42 \mathrm{~h}$ for the maturation of alpaca oocytes.

Key words: in vitro fertilization, oocytes, maturation, alpaca

\section{INTRODUCCIÓN}

El conocimiento sobre la fisiología y endocrinología reproductiva de las especies domésticas ha tenido un incremento sustancial en los últimos años y ha contribuido al desarrollo de procedimientos biotecnológicos aplicados a las distintas especies (Kruip y Van Reenen, 2001). El desarrollo de la técnica de fecundación in vitro (FIV) ha sido el resulta- do de investigaciones sobre los factores involucrados en la maduración del ovocito, la capacitación del espermatozoide y el posterior desarrollo embrionario (Brackett et al., 1982).

La aplicación de tecnologías reproductivas en camélidos sudamericanos se ha incrementado en la última década (Miragaya et al., 2006). El conocimiento de la biología reproductiva de los camélidos ha contribuido 
a su desarrollo y aplicación, aunque en forma limitada y referidas principalmente a la técnica de inseminación artificial con semen fresco (Huanca y Adams, 2007), sincronización y estimulación de la onda folicular (Ratto et al., 2003), y desarrollo de protocolos de estimulación ovárica y transferencia de embriones (Huanca et al., 2009); habiéndose reportado experiencias preliminares sobre maduración y FIV en llamas (Del Campo et al., 1994; Miragaya et al., 2006; Conde et al., 2007; Berland et al., 2011; Trasorras et al., 2013), quedando por realizar estos trabajos en la alpaca.

La maduración del núcleo del ovocito es un proceso que le permite reducir la carga cromosómica de la especie a la mitad, convirtiéndose en una célula haploide. $\mathrm{Al}$ inicio de la maduración, el núcleo del ovocito primario se encuentra bloqueado en la profase de diploteno de la primera división meiótica, estadio de vesícula germinal (GV). En la madurez del folículo y en respuesta a la elevación preovulatoria de la $\mathrm{LH}$, el ovocito reinicia la división meiótica (Gordon, 1994). El núcleo del ovocito entra en diacinésis, y al final de la profase I se disgrega la envoltura nuclear y ocurre la ruptura de la vesícula germinal. Al mismo tiempo se produce una polimerización de los microtúbulos, desaparecen los nucléolos y los cromosomas se condensan y se orientan formando el huso acromático correspondiente a la metafase I. Posteriormente, se separan los cromosomas homólogos, se produce la extrusión del primer corpúsculo polar, y se origina el ovocito secundario con un solo par de cromosomas.

A diferencia de la profase I, que es muy larga, la profase II, prácticamente no existe y el ovocito secundario comienza la segunda división meiótica, entrando directamente a la metafase II, donde la meiosis se interrumpe nuevamente (segundo bloqueo) y el ovocito es expulsado del ovario durante la ovulación. La segunda división meiótica termina cuando el ovocito es penetrado por un espermatozoide y se produce la extrusión del segundo corpúsculo polar.
Los ovocitos de los camélidos presentan características propias, con un citoplasma oscuro, atribuido a la presencia de gotas de lípidos (Del Campo, 1994, citado por Ratto et al., 2005).

La limitada información existente sobre el desarrollo de protocolos de FIV en camélidos domésticos sugiere, en una primera fase, estudiar y evaluar los factores que contribuyan a obtener resultados similares a los observados en otras especies de interés económico. El presente estudio fue realizado con el propósito de evaluar los tiempos de maduración requeridos para obtener ovocitos en estadios de Metafase II (MII) y determinar la tasa de división de ovocitos madurados y fecundados a las 72 horas post fecundación.

\section{Materiales y Métodos}

El estudio se realizó en el Laboratorio de Reproducción Animal de la Facultad de Medicina Veterinaria, Universidad Nacional Mayor de San Marcos, Lima, Perú, y la lectura de las muestras fijadas se realizó en el Laboratorio de Reproducción de la Facultad de Veterinaria, Universidad de Santiago de Compostela, España.

Se colectaron ovarios de alpacas adultas, sacrificadas en el camal municipal del distrito de Nuñoa, Puno, situado a 4000 msnm. Los ovarios se colocaron en un termo conteniendo solución salina $0.9 \%(\mathrm{NaCl})+$ antibiótico antimicótico, a $37{ }^{\circ} \mathrm{C}$, y fueron transportados al laboratorio dentro de las 8 a 10 horas siguientes. Los complejos cumulusovocitos (CCOs) fueros aspirados de folículos con diámetro de 2-6 mm, con ayuda de una jeringa de $10 \mathrm{ml}$ estéril y aguja $18 \mathrm{G} 1 \frac{1 / 2}{2}$ ". El líquido folicular obtenido se depositó en un tubo Falcon de $50 \mathrm{ml}$ cubierto con papel aluminio, y se le dejó reposar por 15 minutos. Luego, el sedimento fue aspirado y colocado en una placa Petri $(90 \times 15 \mathrm{~mm})$ mantenida a $37^{\circ} \mathrm{C}$, para facilitar la búsqueda de CCOs con la ayuda de un estéreo-microscopio a 40x. 


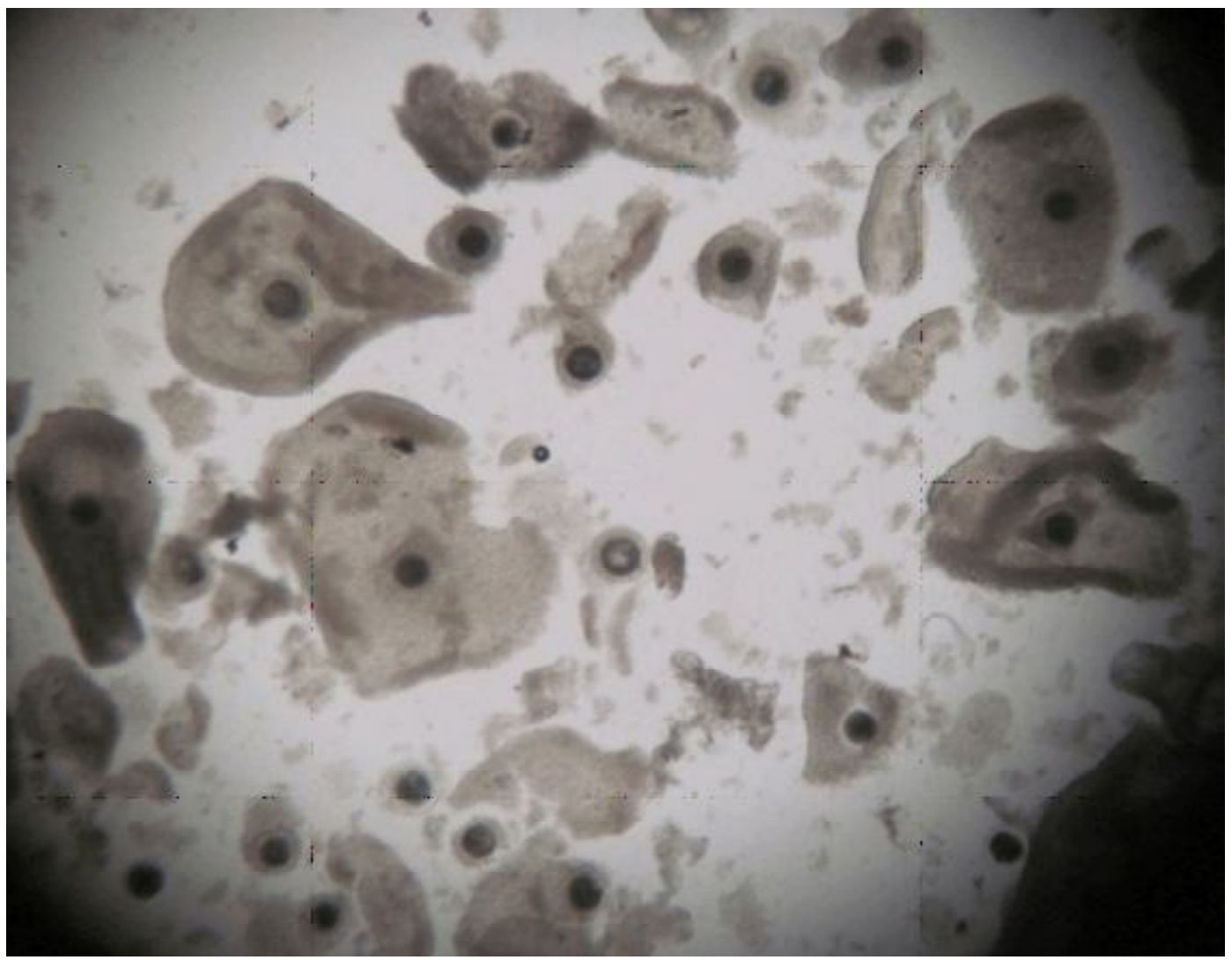

Figura 1. Ovocitos inmaduros de alpaca de grado 1 y 2, según Bertoldo et al. (2010)

Los ovocitos fueron clasificados en base a los criterios señalados por Bertoldo et al. (2010), usando un sistema subjetivo de evaluación que incluye cuatro grados. En el estudio se utilizaron únicamente ovocitos de grado 1 y 2 (Fig. 1). Los grados fueron:

- $\quad$ 1: CCOs con más de tres capas de células del cúmulo compactas y un citoplasma homogéneo.

- 2: CCOs con 2 a 3 capas de células del cúmulo compactas y un citoplasma homogéneo.

- 3: CCOs parcial o totalmente denudados, con citoplasma heterogéneo, con presencia de vacuolas.

- 4: CCOs con células del cúmulos expandido.

\section{Experimento 1: Maduración in vitro}

En la evaluación de la tasa de maduración se utilizaron 502 ovocitos, obtenidos en cinco repeticiones. La maduración se hizo en medio TCM-199, suplementado con $10 \%$ de suero fetal bovino (SFB), $0.5 \mu \mathrm{g} / \mathrm{ml} \mathrm{de} \mathrm{FSH,}$ $10 \mu \mathrm{g} / \mathrm{ml}$ de hCG $0.2 \mathrm{mM}$ de piruvato de sodio, $50 \mu \mathrm{g} / \mathrm{ml}$ de gentamicina y $1 \mu \mathrm{g} / \mathrm{ml}$ de estradiol, según la siguiente distribución: Tratamiento 1 $(\mathrm{n}=118): 30$ horas; Tratamiento $2(\mathrm{n}=138): 34$ horas; Tratamiento 3 ( $\mathrm{n}=125)$ : 38 horas; Tratamiento $4(n=121)$ : 42 horas.

El medio TCM-199 fue colocado en placas Petri en microgotas de $40 \mu$ l, cubiertas con aceite mineral y colocado en incubadora de $\mathrm{CO}_{2}$ por lo menos dos horas antes de su uso. Los ovocitos se lavaron tres veces en 


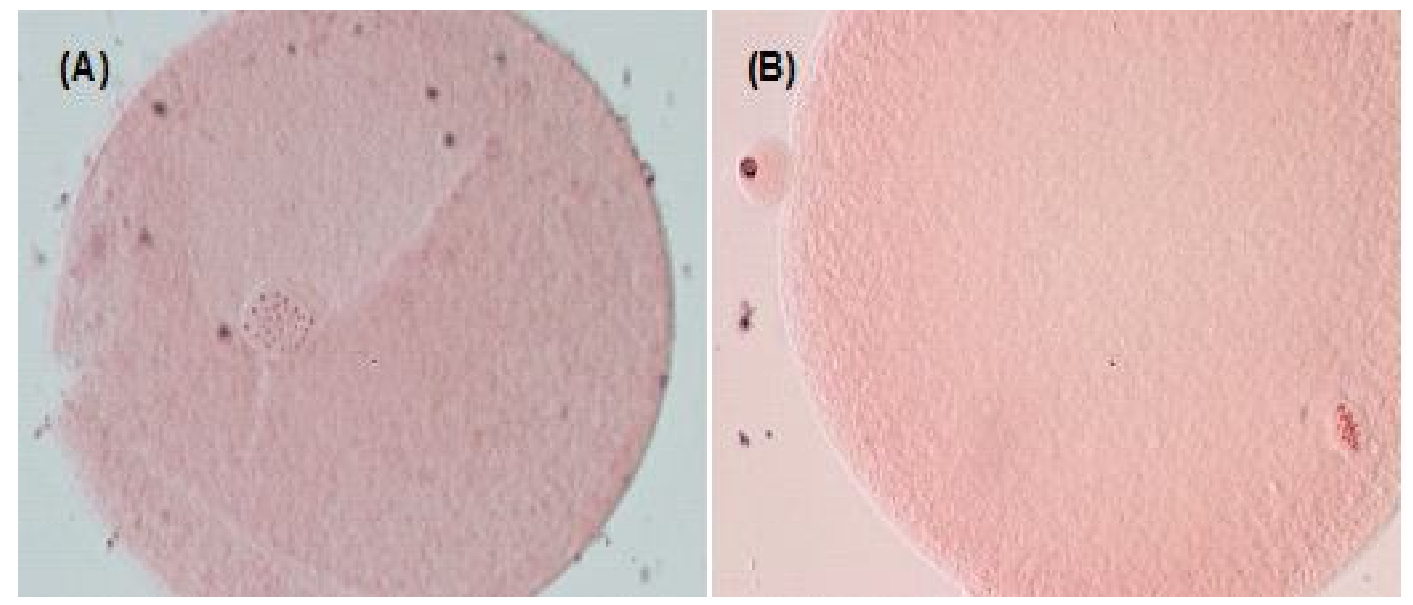

Figura 2. Ovocitos de alpaca en meiosis. A) Estadio Metafase I; B) Estadio Metafase II

medio de lavado pre-maduración y luego, se colocaron 20 ovocitos por gota. La maduración in vitro se realizó en incubadora de $\mathrm{CO}_{2}$, a $39^{\circ} \mathrm{C}, 5 \%$ de $\mathrm{CO}_{2}$ y humedad relativa alta, considerando los tiempos de cultivo para cada tratamiento.

Luego de la incubación, los ovocitos fueron colocados en solución PBS suplementada con $10 \%$ de SFB y $1 \mathrm{mg} / \mathrm{ml}$ de hialuronidasa. Se eliminaron las células del cúmulo mediante agitación en vortex a 2000 rpm por 5 minutos. Los ovocitos desnudos fueron colocados en una solución de fijación conteniendo etanol y ácido acético (3:1), y almacenados a $4{ }^{\circ} \mathrm{C}$ en refrigeración hasta su evaluación.

Para la tinción, se colocaron 5 a 10 ovocitos por lámina, cubiertos con un cubreobjeto sujeto en las cuatro puntas con una mezcla de parafina y vaselina (1:1). Se ejerció una ligera presión sobre el cubreobjetos hasta entrar en contacto con los ovocitos, evitando dañarlos. Se agregó la tinción de orceína al $1 \%$ durante 2-3 minutos, permitiendo que la solución penetre entre el porta y el cubreobjetos por capilaridad. Finalmente, las láminas fueron selladas con esmalte y con ayuda de un microscopio (400x) se determinaron los estadios de maduración nuclear de los ovocitos, considerándose vesícula germinal (GV), metafase I (MI) (Fig. 2a), anafase-telofase I, metafase II (MII) (Fig. 2b), y degenerados.

\section{Experimento 2: Fecundación in vitro}

En la evaluación de la tasa de división a las 72 horas posfecundación se utilizaron 533 ovocitos, obtenidos de cuatro repeticiones. Los ovocitos fueron sometidos a los mismos tiempos de maduración del experimento $1 \mathrm{y}$ fecundados con espermatozoides obtenidos de epidídimos de machos beneficiados en el camal. Luego de cumplirse cada tiempo de maduración, se procedió a retirar y lavar los ovocitos por tres veces. Posteriormente, se colocaron 20 ovocitos por cada gota del medio de fecundación y fueron mantenidos en la incubadora de $\mathrm{CO}_{2}$ a $39^{\circ} \mathrm{C}$ por $1 \mathrm{~h}$ previo a la adición de los espermatozoides.

Los espermatozoides fueron colocados en una gradiente discontinua de Percoll 22.5/ $45 \%$ y sometida a centrifugación a $700 \mathrm{~g}$ por 25 minutos (Abdoon 2001; Khatir et al., 2004). Se retiró el sobrenadante y el pellet formado en la base del tubo fue reconstituido con $30 \mu 1$ de solución TL-Stock. 
A cada gota del medio de fecundación con los 20 ovocitos, se agregó $2 \mu \mathrm{l}$ de la suspensión de espermatozoides, $2 \mu 1$ de heparina $(1 \mathrm{mg} / \mathrm{ml}$ ) y $2 \mu \mathrm{lde}$ PHE ( $2 \mathrm{mM}$ Penicilamina, $1 \mathrm{mM}$ Hipotaurina y $250 \mathrm{mM}$ Epinefrina). Se hizo un co-cultivo por 18 horas a $39^{\circ} \mathrm{C}, 5 \%$ de $\mathrm{CO}_{2}$ y bajo condiciones de máxima humedad. El cultivo in vitro se realizó en medio KSOM-AA, suplementado con $10 \%$ de SFB, $2 \mathrm{mM}$ de piruvato de sodio y $50 \mu \mathrm{g} / \mathrm{mL}$ de gentamicina, preparado en gotas de $30 \mu \mathrm{l}$, sumergidas en aceite mineral y mantenido en incubadora de $\mathrm{CO}_{2}$, por lo menos 12 horas antes de su uso.

Al término del co-cultivo, los presuntos cigotos fueron retirados y se procedió a eliminar las células del cúmulo mediante agitación en vortex a $2000 \mathrm{rpm}$ por $2 \mathrm{~min}$. Se colocó 20 cigotos por gota. La división de células (2 a 8) fue observada a las 72 horas postfecundación (Khatir et al., 2007a).

\section{Análisis Estadístico}

El efecto de los tratamientos (tiempos de maduración) sobre los porcentajes de maduración de ovocitos y división post-fecundación fueron analizados mediante análisis de varianza, con el programa estadístico STATA v. 10.0 .

\section{Resultados y Discusión}

El desarrollo de la tecnología de FIV requiere reducir el tiempo necesario para la maduración nuclear observada en condiciones in vivo. En bovinos y ovinos, se requiere 24 horas para la maduración in vitro para obtener un porcentaje superior al $85 \%$ de ovocitos madurados en estadios de Metafase II (van den Hurk et al., 2005), mientras que en la cerda se requiere de 40 horas para obtener más del $75 \%$ de ovocitos maduros en Metafase II (van den Hurk et al., 2005). En el Cuadro 1 se observa porcentajes decrecientes de ovocitos en Metafase I y una frecuencia creciente de ovocitos de estadios en
Metafase II conforme aumenta el tiempo de maduración. Los porcentajes de ovocitos en estadios de Metafase II más altos se obtuvieron en los tratamientos 3 y 4 con 68.5 y $75.3 \%$, respectivamente $(\mathrm{p}<0.05)$.

Existen pocos estudios en camélidos sudamericanos sobre FIV y los resultados obtenidos en el presente estudio no pueden ser comparados con reportes previos. Se dispone de un estudio en llamas donde se obtuvo $30.4 \%$ de maduración (ovocitos en Metafase II) después de 30 horas de cultivo (Del Campo et al., 1994), pero el objetivo no fue la determinación del tiempo de maduración, sino que estuvo orientado a demostrar la factibilidad de desarrollar un protocolo de fecundación in vitro en camélidos, así como determinar la capacidad fecundante de espermatozoides obtenidos de epidídimos, que sirvan como base para el desarrollo de protocolos de FIV. En otro estudio se obtuvo 78\% de ovocitos en estadio de Metafase II con un tiempo de maduración in vitro de 28 horas (Ratto et al., 2005); sin embargo, en dicho estudio se utilizaron tratamientos hormonales previos para inducir el crecimiento folicular, contribuyendo a la maduración in vivo de los ovocitos.

La necesidad de un tiempo de maduración prolongado en los camélidos podría ser explicado por las características propias de la especie, toda vez que son especies de ovulación inducida, que requieren de estímulos externos como la cópula y que la ovulación in vivo ocurre a las 30 horas posteriores a la aplicación del estímulo (Huanca et al., 2001).

Estudios realizados en una especie similar, el dromedario, señalan que los ovocitos requieren un tiempo óptimo de maduración in vitro de 36 horas, siendo el rango de 32 a 44 horas para obtener porcentajes mayores a $75 \%$ de ovocitos madurados en estadios de Metafase II (Abdoon, 2001; Khatir et al., 2004, 2007a,b; Wani y Nowshari, 2005). Estos resultados, así como el porcentaje creciente de ovocitos degenerados conforme se 
Cuadro 1. Tasa porcentual de maduración nuclear (Metafase II $^{1}$ ) de ovocitos de alpacas

\begin{tabular}{cccccc}
\hline $\begin{array}{c}\text { Tiempo de } \\
\text { maduración }\end{array}$ & $\begin{array}{c}\text { Vesícula } \\
\text { germinal }\end{array}$ & Metafase I & $\begin{array}{c}\text { Anafase- } \\
\text { telofase }\end{array}$ & Metafase II & Degenerado \\
\hline T1 $(\mathrm{n}=118)$ & $5.3 \pm 1.3$ & $43.8 \pm 11.7$ & $9.0 \pm 13.9$ & $26.3^{\mathrm{a}} \pm 5.4$ & $15.6 \pm 9.9$ \\
$\mathrm{~T} 2(\mathrm{n}=138)$ & $10.6 \pm 7.1$ & $23.1 \pm 8.72$ & $12.4 \pm 8.0$ & $52.6^{\mathrm{b}} \pm 6.7$ & $1.4 \pm 3.2$ \\
$\mathrm{~T} 3(\mathrm{n}=125)$ & $6.1 \pm 6.3$ & $7.9 \pm 3.3$ & $12.6 \pm 5.6$ & $68.5^{\mathrm{b} . \mathrm{c}} \pm 10.6$ & $4.8 \pm 3.9$ \\
$\mathrm{~T} 4(\mathrm{n}=121)$ & 0 & $9.9 \pm 10.4$ & $2.3 \pm 2.2$ & $75.3^{\mathrm{c}} \pm 11.9$ & $12.4 \pm 9.5$ \\
\hline
\end{tabular}

T1: 30; T2: 34; T3: 38; T4: 42 horas

a,b,c Superíndices diferentes en el estadio de Metafase II son estadísticamente diferentes $(p<0.05)$

${ }^{1}$ Estadio de maduración nuclear

Cuadro 2. Tasa porcentual de división de ovocitos de alpacas posfecundación a diferentes horas de maduración nuclear

\begin{tabular}{ccc}
\hline $\begin{array}{c}\text { Tiempo de maduración de } \\
\text { ovocitos }\end{array}$ & $\begin{array}{c}\text { Ovocitos } \\
(\mathrm{n})\end{array}$ & $\begin{array}{c}\text { Porcentaje de división a las } \\
72 \text { horas }\end{array}$ \\
\hline T1 $(30 \mathrm{~h})$ & 131 & $9.5 \pm 4.8$ \\
T2 $(34 \mathrm{~h})$ & 122 & $8.1 \pm 5.8$ \\
T3 $(38 \mathrm{~h})$ & 139 & $15.6 \pm 9.2$ \\
T4 $(42 \mathrm{~h})$ & 141 & $19.8 \pm 8.0$ \\
\hline
\end{tabular}

${ }^{1}$ Sin diferencia estadística entre tratamientos

incrementa los tiempos de maduración concuerdan con los del presente estudio. El incremento en la frecuencia de ovocitos degenerados puede ser explicado en parte por las condiciones en que se realiza el cultivo, donde se utilizan concentraciones de oxígeno de $20 \%$, con la consiguiente generación de sustancias oxígeno reactivas (ROS). Sin embargo, no se han encontrado posibles explicaciones al $15.6 \%$ de ovocitos degenerados con 30 horas de maduración.
Los resultados de división de ovocitos posfecundación a diferentes tiempos de maduración se observan en el Cuadro 2. Se puede observar una tendencia al aumento en tasa de división de ovocitos conforme aumenta el tiempo de maduración, pero estas diferencias no fueron estadísticamente significativas, dada la gran variabilidad de los promedios. Por otro lado, los resultados fueron bastante bajos, especialmente si se compara con los resultados obtenidos en camellos. Sin 
embargo, es posible que estas diferencias se deban a posibles deficiencias en la implementación de la técnica, especialmente en las condiciones de fecundación y cultivo posfecundación.

\section{Conclusiones}

- El tiempo de maduración in vitro de ovocitos procedentes de ovarios de alpacas beneficiadas en camal se encuentra en un rango de 38 y 42 horas, para obtener 68.5 y $75.3 \%$ de ovocitos en Metafase II, respectivamente.

- La tasa de división de ovocitos fecundados in vitro, con espermatozoides obtenidos directamente de epidídimo de machos beneficiados en camal, fue de 15.6 y $19.8 \%$ para las 38 y 42 horas de maduración, respectivamente.

\section{Literatura Citada}

1. Abdoon ASS. 2001. Factors affecting follicular population, oocyte yield and quality in camels (Camelus dromedarius) ovary with special reference to maturation time in vitro. Anim Reprod Sci 66: 71-79.doi: 10.1016/j.theriogenology.2010.11.047

2. Berland MA, Von Baer A, Ruiz J, Parraguez VH, Morales P, Adams GP,

Ratto MH. 2011. In vitro fertilization and development of cumulus oocytes complexes collected by ultrasoundguided follicle aspiration in superstimulated llamas. Theriogenology 75: 1482-1485.

3. Bertoldo M, Holvoake PK, Evans G, Grupen CG. 2010. Oocyte developmental competence is reduced in sows during the seasonal infertility period. Reprod Fert Develop 22: 122-1229.doi: 10.1071/RD10093

4. Brackett BG, Bousquet D, Boice ML, Donawick WJ, Evans JF, Dressel MA. 1982. Normal development following in vitro fertilization in the cow. Biol Reprod 27: $147-158$

5. Conde PA, Herrera C, Trasorras VL, Giuliano SM, Director A, Miragaya MH, Chaves MG et al. 2007. In vitro production of llama (Lama glama) embryos by IVF and ICSI with fresh semen. Anim Reprod Sci 109: 298-308.

6. Del Campo MR, Del Campo CH, Donoso MX, Berland M, Mapletoft RJ. 1994. In vitro fertilization and development of llama (Lama glama) oocytes using epididymal spermatozoa and oviductal cell co-culture. Theriogenology 41: 1219-1229.

7. Gordon I. 1994. Laboratory production of cattle embryos. Wallinford, UK: CAB International. $626 \mathrm{p}$.

8. Huanca W, Adams G. 2007. Semen collection and artificial insemination in llamas and alpacas. In: Current therapy in large animal theriogenology. $2^{\text {nd }} e d$. New York: Saunders. p 869-873.

9. Huanca W, Cárdenas O, Olazábal C, Ratto M, Adams G. 2001. Efecto hormonal y empadre sobre el intervalo a la ovulación en llamas. Rev Inv Vet Perú (Supl 1): 462-463.

10. Huanca W, Cordero A, Huanca T, Cárdenas O, Adams GP, Ratto MH. 2009. Ovarian response and embryo production in llamas treated with equine chorionic gonadotropin alone or with a progestin-releasing vaginal sponge at the time of follicular wave emergence. Theriogenology 72: 803-808. doi: 10.1016/j.theriogenology.2009.05.019

11. Khatir H, Anouassi A, Tibary A. 2004. Production of dromedary (Camelus dromedarius) embryos by IVM and IVF and co-culture with oviductal or granulosa cells. Theriogenology 62: 11751185.doi:10.1016/j.theriogenology.2004.01.016

12. Khatir H, Anouassi A, Tibary A. $2007 a$. Effect of follicular size on in vitro developmental competence of oocytes and viability of embryos after transfer in the dromedary (Camelus dromedarius). Anim Reprod Sci 99: 413-420. 
13. Khatir H, Anouassi A, Tibary A. 2007 b. Quality and developmental ability of dromedary (Camelus dromedarius) embryos obtained by IVM/IVF, in vivo matured/IVF or in vivo matured/ fertilized oocytes. Reprod Dom Anim 42: 263-270.

14. Kruip TAM, Van Reenen CG. 2001. Biotechnology of reproduction and farm animals welfare. In: Sustainable animal production. [Internet]. Available in: http:/ /www.agriculture.de

15. Miragaya MH, Chaves MG Agüero A. 2006. Reproductive biotechnology in South American camelids. Small Ruminant Res 61:299-310. doi: 10.1016/ j.smallrumres.2005.07.017

16. Ratto M, Berland M, Huanca W, Singh J, Adams GP. 2005. In vitro and in vivo maturation of llama oocytes. Theriogenology 63: 2445-2457.
17. Ratto MH, Singh J, Huanca W, Adams GP. 2003. Ovarian follicular wave synchronization and pregnancy rate after fixed-time natural mating in llamas. Theriogenology 60: 1645-1656.

18. Trasorras V, Giuliano S, Miragaya M. 2013. In vitro production of embryos in South American camelids. Anim. Reprod Sci 136: 187-193. doi:10.1016/j.anireprosci.2012.10.009

19. van den Hurk R, Zhao J. 2005. Formation of mammalian oocytes and their growth, differentiation and maturation within ovarian follicles. Theriogenology 63: 1717-1751.

20. Wani NA, Nowshari MA. 2005. Kinetics of nuclear maturation and effect of holding ovaries at room temperature on in vitro maturation of camel (Camelus dromedarius) oocytes. Theriogenology 64: 75-85. 